\title{
Analysis of External Water Pressure for a Tunnel in Fractured Rocks
}

\author{
Ze-jun Liu, ${ }^{1}$ Yong Huang, ${ }^{2}$ Ding Zhou, ${ }^{1,3}$ and Hong Ge ${ }^{1}$ \\ ${ }^{1}$ Faculty of Architecture and Civil Engineering, Huaiyin Institute of Technology, Huaian 223003, China \\ ${ }^{2}$ School of Earth Science and Engineering, Hohai University, Nanjing 210098, China \\ ${ }^{3}$ College of Civil Engineering, Nanjing Tech University, Nanjing 211816, China \\ Correspondence should be addressed to Ding Zhou; dingzhou57@yahoo.com
}

Received 16 October 2016; Accepted 10 January 2017; Published 30 January 2017

Academic Editor: Marco Petitta

Copyright (c) 2017 Ze-jun Liu et al. This is an open access article distributed under the Creative Commons Attribution License, which permits unrestricted use, distribution, and reproduction in any medium, provided the original work is properly cited.

External water pressure around tunnels is a main influential factor in relation to the seepage safety of underground chambers and powerhouses which make managing external water pressure crucial to water conservation and hydropower projects. The equivalent continuous medium model and the discrete fracture network (DFN) model were, respectively, applied to calculate the seepage field of the study domain. Calculations were based on the integrity and permeability of rocks, the extent of fracture development, and the combination of geological and hydrogeological conditions in the Huizhou pump-storage hydropower station. The station generates electricity from the upper reservoir and stores power by pumping water from the lower to the upper reservoir. In this paper, the external water pressure around the cavern and variations in pressure with only one operational and one venting powerhouse were analyzed to build a predictive model. The results showed that the external water pressure was small with the current anti-seepage and drainage system that normal operation of the reservoir can be guaranteed. The results of external water pressure around the tunnels provided sound scientific evidence for the future design of antiseepage systems.

\section{Introduction}

External water pressure is defined as a boundary load where the groundwater pressure acts on the outer edge of a tunnel lining $[1,2]$. The value of the external water pressure can be obtained by analyzing the seepage field of the tunnel. Assuming that the hydraulic head in the contact surface is $h$, the external water pressure can be defined as $f_{w}=\gamma\left(h_{c}-z_{c}\right)$. There are some common principles that can ensure the safety of groundwater resources and the environment surrounding the tunnel lining of large hydraulic mountain tunnels [3-5]. A method that combines mixed blocking and discharging can be adopted when a method that uses pure discharging cannot be used due to special conditions, such as decreasing of the water table around the tunnel. The water pressure at the site was studied and based on previous water conservation and waterpower projects in China. An appropriate design code was formulated for the project. The main calculation methods of external water pressure in the tunnel linings are described in the following sections.
The Reduction Coefficient Method. According to the "Hydraulic Tunnel Design Code" (SL279 2002), groundwater pressure is defined as the volume force of groundwater on the surrounding rocks and linings during the seepage process. For tunnels under simple hydrogeological conditions, groundwater pressure on the outer edge of the lining can be calculated by measuring the water column height below the groundwater table along the length of the tunnel and by using a corresponding reduction coefficient for the tunnels. The reduction coefficient is defined as the ratio of actual water pressure to the maximum water pressure and is quoted as a value ranging from 0 to 1 . The external water pressure is determined by multiplying the hydrostatic pressure from the groundwater table to the tunnel axis by the reduction coefficient $\beta$.

Zhang $[6,7]$ developed a new approach to obtain the correct coefficient on the basis of the standardizing reduction coefficient. Some disadvantages of the external water pressure reduction coefficient include the following: (1) it is difficult for designers to choose the $\boldsymbol{\beta}$ parameter because of its 
large amplitude, (2) $\beta$ cannot be used in projects that have extremely small permeability as the reduction coefficient $\boldsymbol{\beta}$ is established based on conditions of a normal concrete lining in which cracks are present, and (3) the water pressure of a point in the initial seepage field does not equal the hydrostatic water pressure on the groundwater table because of different terrain and geological conditions in actual cases. It is difficult to determine external water pressure using the reduction coefficient from a former code, especially when the groundwater table in question lies along the tunnel or the state of groundwater is unknown, for example, in unconfined water, water between layers, or perched water. Furthermore, the impact of anti-seepage or drainage galleries and drainage holes on the water level is not considered in this method.

The Analytical Method. The initial stress on the lining can be regarded as the hydrostatic status if the surrounding rock is assumed to be comprised of homogeneous and isotropic elastoplastic media. The pore water pressure on the lining and grouting area can be derived using Darcy's Law based on the surrounding rock model [8-13]. The external water pressure on the tunnel lining can be calculated using a theoretical analysis method that assumes the grouting area of the surrounding rock is homogeneous; however, this method is not suitable for real projects under complex geological conditions.

The Semianalytical Method. The details of the semianalytical method are as follows: firstly, a hydrogeological conceptual model of a discharging tunnel was established and water inflow was predicted using an empirical method [14-16]. Water inflow was substituted into a two-dimensional section seepage model of the surrounding tunnel rock to simulate the distribution of a seepage field in the surrounding rocks during draining. Finally, the external water pressure around the tunnel was calculated using the reduction coefficient method. A numerical method was used to simulate the tunnel seepage field during draining of the seepage field of the surrounding rocks. Throughout this process the external water pressure in the lining was obtained.

The water inflow of a tunnel was determined using the analytical numerical method, and the tunnel set as a secondtype boundary condition for numerical calculations where the flux was known in the boundary condition. Some errors exist when using the analytical method to determine tunnel water inflow as it is particularly difficult to define the water level when a tunnel has already been built. In addition, the effect of the drainage gallery is not considered in the model. In this case, the tunnel was regarded as a seepage surface instead of a constant-head boundary condition where the hydraulic head was assumed equal to its position height even when it was higher than the actual position height. The seepage surface was determined using an iterative method.

The Hydrogeochemical Method. The hydrogeochemical method considers the relationship between the external water pressure and the $\mathrm{CO}_{2}$ partial pressure in a groundwater chemical field. The results from field tests reveal that $\mathrm{CO}_{2}$ partial pressure and groundwater pressure obey a linear law in the same water body or geological element. Therefore, the $\mathrm{CO}_{2}$ partial pressure in a borehole under the same hydrogeological conditions can be measured and the equations between the $\mathrm{CO}_{2}$ partial pressure and the hydraulic head can be derived. The water pressure in a seepage area can be acquired indirectly by measuring $\mathrm{CO}_{2}$ partial pressure on the tunnel seepage point [17]. This is a new method to calculate external water pressure.

The Seepage and Stress Coupling Methods. This method considers the combined effects of surrounding rocks and linings on groundwater. The effect of groundwater on surrounding rocks and linings was calculated using seepage theory. The coupling effect of surrounding rocks and linings can be examined through an analysis of in situ stress and groundwater penetration during tunnel excavation [18-21]. Since the coupling effect is more important than external water pressure on linings, it can be applied to analyze the stress on the tunnel lining structure and the stability of surrounding rocks.

Investigators have made considerable progress after much research on the seepage and stress coupling field coupled models. Noorishad et al. [22, 23] presented a continuous porous media seepage and stress field coupling model. Oda [24] established a model that couples seepage and stress field in rock masses using a hydraulic conductivity tensor based on joint statistics. Ohnishi and Ohtsu [25] studied a seepage and stress coupling method in a discontinuous joint rock mass. Wu and Zhang [26] proposed a lumped parameter and fracture network model of rock mass seepage and stress field coupling. The development of rock hydraulics has been promoted in a quantitative direction through these models as the coupled seepage and stress field of linings are not adequate after tunnel excavation and structure support [27-29].

The seepage and stress coupling analysis method mainly investigates the effect of groundwater on surrounding rocks and linings. When the effect on surrounding rocks and linings from groundwater was calculated using a seepage theory, the coupling effect on surrounding rocks and linings from the groundwater penetration force can be analyzed through in situ stress caused by tunnel excavation. In this method, surrounding rocks and linings are regarded as a whole that shares external water pressure, except in regions under high water pressure conditions where there will be many fractures or fissures between the surrounding rocks and linings. In the case of such conditions, external water pressure mainly occurs on the linings instead of on the rocks and linings together.

The purpose of this paper was to develop a coupled model to simulate groundwater flow in fractured rocks based on geological and hydrogeological conditions. External water pressure of a tunnel was also calculated to evaluate the seepage stability of a diversion pipeline.

\section{Area of Study}

2.1. Location of the Study Area. The Huizhou pumped storage water power station is located in Boluo county, Huizhou city, Guangdong province. It is $112 \mathrm{~km}$ away from Guangzhou, 
$20 \mathrm{~km}$ from Huizhou, and $77 \mathrm{~km}$ from Shenzhen and has a total capacity of 2,400 MW. The main dams in the upper and lower reservoirs are roller-compacted concrete gravity dams. There are two plants, A and B, located behind the middle of the pipeline in the plant system with a minimum spacing of $150 \mathrm{~m}$ to recharge water. The two powerhouses are both $152 \mathrm{~m}$ in length, $21.5 \mathrm{~m}$ wide, and $49.4 \mathrm{~m}$ high. The elevation of the powerhouse vault is $169.9 \mathrm{~m}$. The diameter of high pressure tunnel is $8.0 \mathrm{~m}$. The middle elevation of it ranges from 137.87 to $135.62 \mathrm{~m}$ with the maximum hydrostatic head at $630 \mathrm{~m}$. When the power station is operating normally, the water from the upper reservoir flows to the powerhouse to generate electricity and the tail water flows to the lower reservoir. This water is then pumped to the upper reservoir through the waterlines. The diversion tunnel, high pressure tunnel, high pressure branch pipes, and tailrace tunnel are made from a reinforced concrete lining except for the steellined high pressure branch pipes and the tailrace pipes for water diversion in the water power tunnel.

2.2. Geology Information. The lithology disclosed in the powerhouse region is granite, mixed rock, and veins. The medium-fine and medium-coarse grained granite is from the fourth Himalayan period and is fleshy red in color with strong permeability owing to high porosity. The minerals in this region consisted of potassium feldspar (30-50\%), plagioclase (20-35\%), quartz (20-35\%), and black mica (1-8\%). The geological age of the mixed rock is between the Caledonian and Himalayan periods. The thickness of this rock is between 35.3 and $46.5 \mathrm{~m}$ according to data obtained from different boreholes and its permeability is lower than that of granite. The spaces of some fractures and faults were intruded diorite vein, granitic diorite vein, quartz, fluorite, and calcite veins, which results in weak permeability of fractures and faults.

There are 67 faults disclosed by the exploratory cave in the powerhouse region in the north-east (NE), north-west (NW), and north north-west (NNW) directions (Figure 1). The directions of joints and fractures are the same as those of the faults in the powerhouse region which are mainly in the NNE and NW directions. Faults and fractures are classified into four groups according to their strikes. (1) The NNE group appears mainly in exploration caves, such as PD01-1, PD01-2, PD01-3, and PD01-6 in an east-west or nearly eastwest direction (Figure 1). The tendency is $\mathrm{N} 5-20^{\circ} \mathrm{E}$ with a more SE tendency than a NW tendency, and the dip angle is from almost 60 to $80^{\circ}$. (2) The NW group appears mainly in exploration caves PD01, PD01-2, PD01-3, PD01-4, and PD016 , and the fissures show a tendency of $\mathrm{N} 35-60^{\circ} \mathrm{W}$ with a more SE tendency than a NW tendency, and the dip angle is 60 to $85^{\circ}$.

\subsection{Hydrogeological Conditions}

2.3.1. Permeability of the Rock Mass. Field test data comprising 392 total pump-in tests from 23 boreholes in the underground powerhouse region showed conditions of very low permeability, partial low permeability, and a small portion of medium permeability in mixed rock and granite (as seen in Figure 2). The very low permeable rock mass,

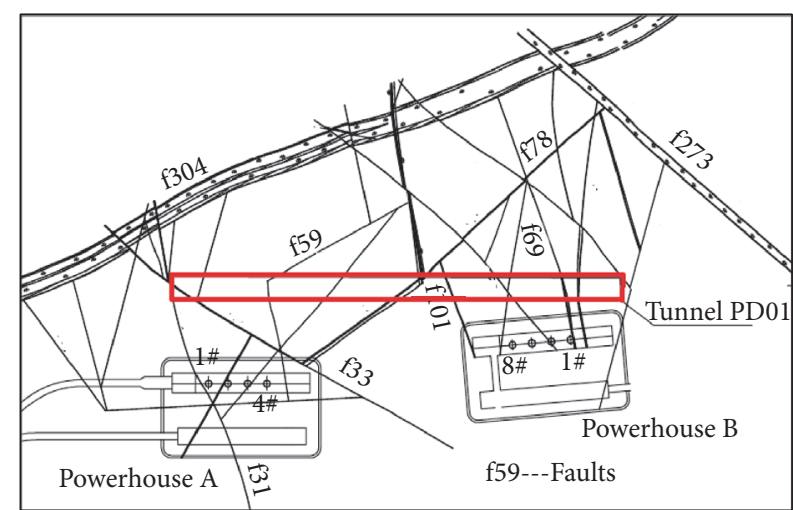

FigURE 1: Location of the main faults in the powerhouse area.

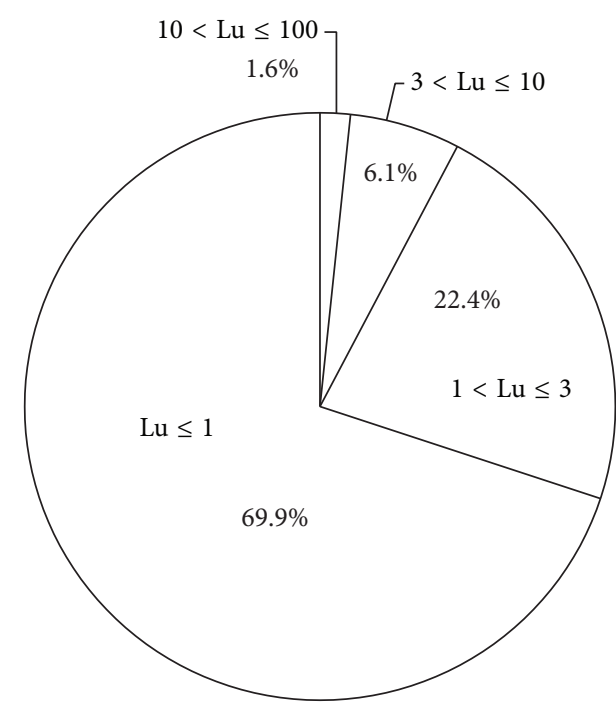

FIGURE 2: Statistical pie chart of rock permeability in the underground powerhouse domain.

lower permeable rock mass, and medium permeable rock mass were present at $69.9 \%, 28.5 \%$, and $1.6 \%$, respectively. There were no highly permeable rocks in the powerhouse region being found and the permeability rate was greatest when the borehole was close to the ground surface, but as depth increased and height decreased, water permeability was reduced. Additionally, the permeability rate increased in some test areas because of fault zones and dykes. The rock permeability of boreholes ZK2002 and ZK2085 changed with depth and time in the powerhouse area, as shown in Figure 3.

Permeability of rock can be classified into three categories: (1) highly permeable zones, which include rock in completely weathered and strongly weathered zones, fault f304 fracture zones, fault with water permeability in NE direction, and fault cut by NW direction rock and f304, (2) low permeability zones, which comprise weak weathered rock mass, and (3) very low permeable zones which are slightly weathered zones with fresh rock mass and dykes under a good condition. 


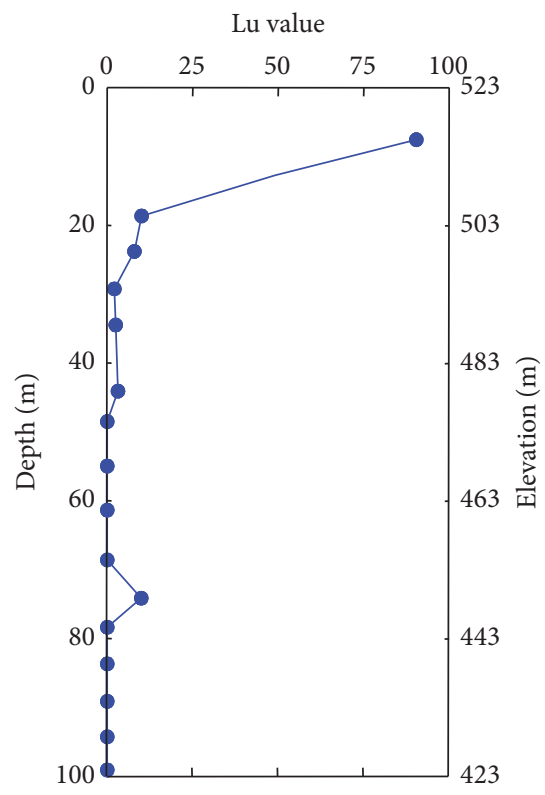

(a) ZK2002

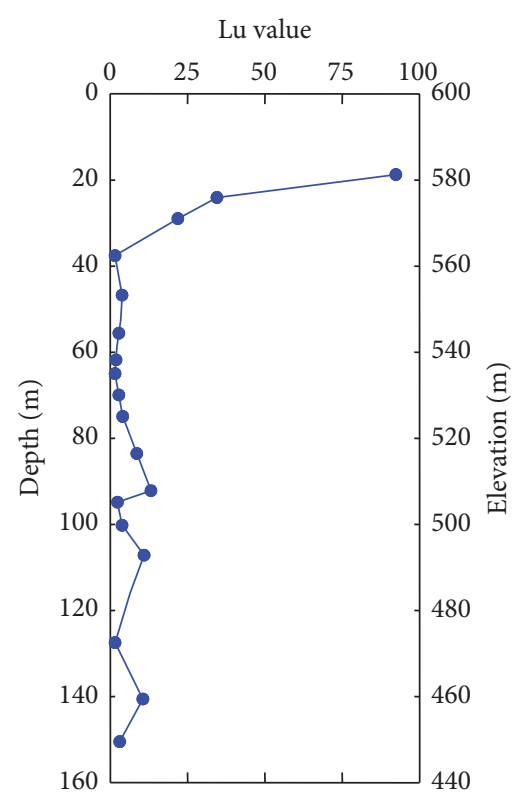

(b) ZK2085

FIGURE 3: Change of rock permeability with depth changes in the powerhouse domain.

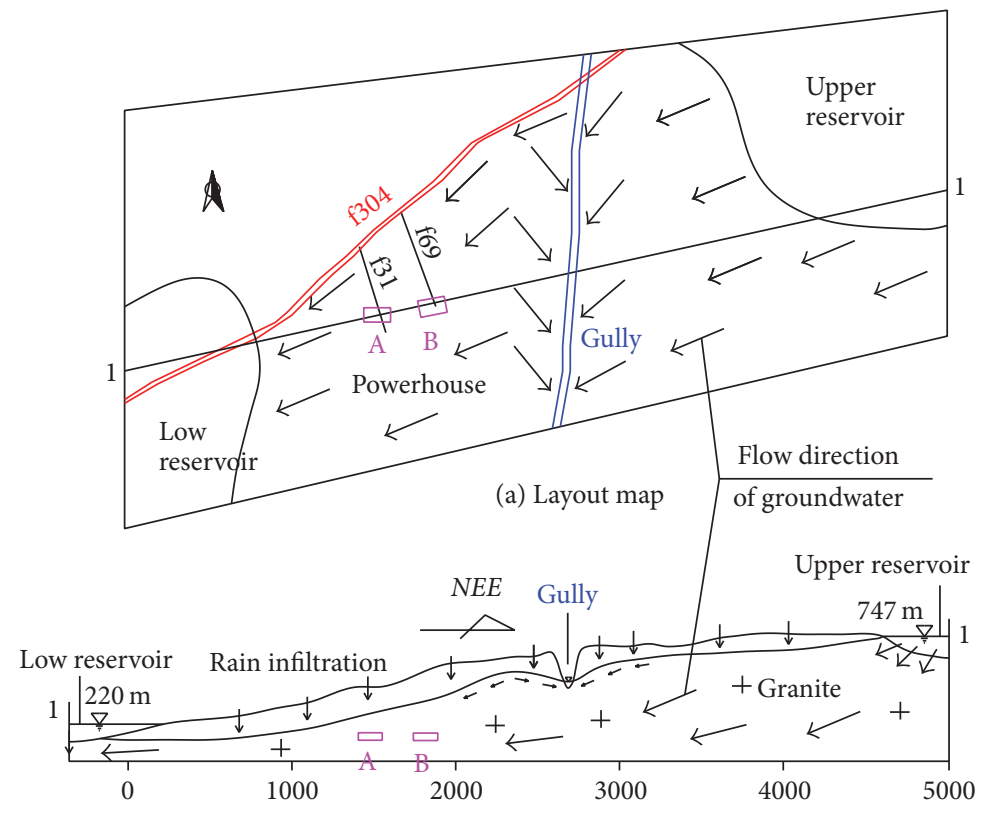

(b) Cross-section map

FIGURE 4: Conceptual map of the hydrogeological model.

2.3.2. Groundwater Recharge, Runoff, and Discharge Conditions. The recharge sources of underground powerhouses are precipitation and water from the upper reservoir through fault f304. Water discharged from the upper reservoir flows into fault f304 and into underground powerhouses through a fault in the NW direction, such as $\mathrm{f31}$ and $\mathrm{f} 69$ because f304 is closer to the underground powerhouses (Figure 4). Based on all things considered, f304 might be the only approach for water from the upper reservoir to flow into the powerhouses. The plant area can be divided into two separate hydrogeological units on both sides of a gully by analyzing the permeability, hydrogeological structure of rock mass, and hydrogeological conditions.

In natural conditions, the main recharge source of the upper reservoir is precipitation and the water from higher level reservoirs. They were discharged to the gully, the powerhouses, and the lower storage reservoir. Precipitation is also the main recharge source of the powerhouses and the lower 
storage reservoir. Part of the water in the powerhouses and the lower storage reservoir flows into the gully, the shallow water body in earth's surface, and deeper underground for discharge, as shown in Figure 4.

\section{Calculation Methods of External Water Pressure}

3.1. The Equivalent Continuum Model. Research results show that groundwater movement changes with time and space in fractured rocks complies with the relevant laws of seepage. In such cases, the hydrogeological model can be assumed as a continuum of heterogeneous anisotropic media and the three-dimensional movement of groundwater in rocks based on the following control equation:

$$
\nabla(K \nabla H)=\mu_{s} \frac{\partial H}{\partial t}
$$

where $\nabla$ is the Hamilton operator, $K$ is the permeability tensor, $H$ represents the hydraulic head at any point in the seepage field, $\mu_{s}$ is the storage rate, and $t$ is the time.

The study area $\Omega$ was discretized by a hexahedron with eight nodes. The weighted residual of the governing equation (1) in the whole study area is zero, and the algebraic equations of the whole seepage field could be obtained as follows:

$$
[G]\{H\}+[P]\left\{\frac{d H}{d t}\right\}=\{F\},
$$

where $[G]$ is the total seepage matrix (conduction matrix), $\{H\}$ is a hydraulic head array at an unknown node, $[P]$ is the storage matrix, and $\{F\}$ denotes the known flux boundary. In this case, $d H / d t$ can be replaced by time discretization; that is,

$$
\frac{d H}{d t} \approx \frac{H_{(t+\Delta t)}-H_{(t)}}{\Delta t},
$$

where $\Delta t$ is the time step. obtain

An implicit difference scheme was applied to (3); we

$$
[G]\left\{H_{t+\Delta t}\right\}+[P]\left\{\frac{H_{(t+\Delta t)}-H_{t}}{\Delta t}\right\}=\{F\} .
$$

Equation (4) can thus be rewritten as follows:

$$
\left\{[G]+\frac{1}{\Delta t}[P]\right\}\left[H_{t+\Delta t}\right]=\frac{1}{\Delta t}[P]\left\{H_{t}\right\}+\{F\} .
$$

The distribution of the seepage field in the study area can be solved by using (5).

3.2. The DFN Model. In the fractured network seepage model, the intersection of fractures can be regarded as nodes and the fractures between nodes which are seen as elements. The seepage equations were built to account for either a total flow rate of zero (steady flow) or a flow change that may be equal to the storage capacity from each line element to the shared node (unsteady flow). The mathematical model

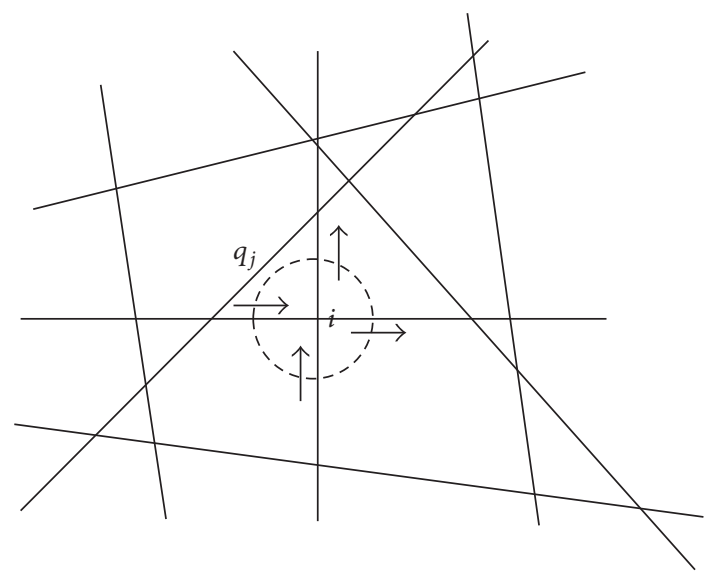

FIGURE 5: Schematic diagram of the balanced fracture elements.

of groundwater flow using a fracture network was built by combining the initial conditions and boundary conditions [30-32]. A schematic diagram of a rock fracture network was then obtained and shown in Figure 5, where a dotted-line circle indicates the balanced domain of the fracture element.

A characterized element domain was formed at the center point $i$. The domain, including the $i$ node and a closed curve, was formed at the midpoint of each element of a connecting line. The inflow and outflow from each element of a connecting line can be defined as $q_{j}\left(j=1,2, \ldots, N^{\prime}\right)$, and the vertical recharge from each element of a connecting line in the characterized element domain denotes $w_{j}(j=$ $\left.1,2, \ldots, N^{\prime}\right)$, and the source-sink term on node $i$ is $Q_{i}$. The flow differential value of the characterized element domain per time unit is equal to the amount of water storage changes.

The equilibrium equations of the characterized element domain can be written as

$$
\sum_{j=1}^{N^{\prime}} q_{i j}+\sum_{j=1}^{N^{\prime}} w_{i j}+Q_{i}=d_{i} \frac{\Delta H_{f_{i}}}{\Delta t}, \quad i=1,2, \ldots, N .
$$

The pressure difference remains conserved in a closed loop and can be written as

$$
\sum_{k_{c}} l_{j} I_{j}=0, \quad c=1,2, \ldots, r,
$$

where $H_{f_{i}}$ is the hydraulic head of node $i, N^{\prime}$ is the number of a line element (the number of pipelines centered at node $i$ ), and $k_{c}$ is the number of fracture sections with formed loops, that is, the dimensions of loops.

In $d_{i}=\left(S_{i} / 2\right) \sum_{j=1}^{N^{\prime}} e_{j} l_{j}, S_{i}$ is the elastic storage (releasing water) coefficient of a fracture in the characterized element domain center at note $I, e_{j}$ and $l_{j}$ are the width of a fracture and the length of a line element, and $I_{j}$ is the hydraulic gradient of fracture element.

The matrix form of a seepage equation in a seepage flow field can be written as

$$
[C]\left\{H_{f}\right\}-[A]\{W\}+\{Q\}+[D] \frac{d H_{f}}{d t}=0,
$$


where $\{W\}$ is the vector of vertical recharge on a fractured line element, $\{D\}$ is the water storage matrix in the fractures, and $A=\left\{a_{i j}\right\}$ indicates the connection matrix of a fracture network. All of these terms describe the connection relationship between line elements and nodes in a fracture network system, where $A$ is the matrix element and $a_{i j}$ is defined as follows: $j$ is $0,-1$, and 1 on three different conditions, there is no connection between line element $j$ and node $i$, while the connection between line element $j$ and node $i$ points to opposite directions of node $i$, and the connection between line element $j$ and node $i$ points to $i$ direction, respectively. $d H_{f} / d t$ can be defined as $d H_{f} / d t \approx\left(H_{f}^{t+\Delta t}-H_{f}^{t}\right) / \Delta t$ and can be rewritten as

$$
\begin{aligned}
& \left([C]+\frac{1}{\Delta t}[D]\right)\left\{H_{f}^{t+\Delta t}\right\} \\
& =[A]\{W\}+\frac{1}{\Delta t}[D]\left\{H_{f}^{t}\right\}-\{Q\} .
\end{aligned}
$$

3.3. Calculation of the Coupling Model. The coupling conditions for an equivalent continuum model and a random discrete fracture network model are as follows: (1) the water volume balance between inflow and outflow in a fracture surface in unit time, that is, conservation of flow in a fracture intersection, and (2) the continuum of a hydraulic head in a fracture intersection, that is, $\left.H_{e i}\right|_{F i}=\left.H_{f j}\right|_{F j}(i \neq j)$. The following iterative methods were employed to solve the mentioned coupling models just described: (1) the initial and boundary conditions in the discrete media domain are substituted into (5) to obtain the hydraulic head $H_{e}$ in the continuum media domain; (2) the flow contribution of coupling terms can be acquired using $H_{e}$, and then $H_{f}$ can be solved for after substituting the contribution into (9); (3) $H_{e}$ can be solved by substituting $H_{f}$ into (5); and finally, (4) the above steps are repeated until the accuracy requirement is satisfied.

3.4. Calculation Region and Boundary Conditions. Point $\mathrm{O}$ at the cross intersection, located in the south-eastern direction of powerhouse B shown in Figure 6, is set as the origin of coordinates in the calculation domain. Positive $Y$ direction points toward the north, positive $X$ points to the east, and positive $Z$ is set vertically upward. The calculation domain is selected along the positive $X$ direction to the upper reservoir and the negative $X$ direction to the lower reservoir, while the $Y$ direction extends around $1000 \mathrm{~m}$ from the center of the powerhouse to the watershed of the station region.

Boundary conditions in the upper reservoir were set as first boundary conditions with a normal storage water level of $762 \mathrm{~m}$ and a dead water level of $740 \mathrm{~m}$. Boundary conditions in the lower reservoir were also set as first boundary conditions with a normal storage water level of $231 \mathrm{~m}$ and a dead water level of $205 \mathrm{~m}$. Other boundaries can be regarded as streamlined boundaries as they were located at the position of the watershed. The study domain was meshed by two types of grids as equivalent continuum media and coupled discrete media model were employed to simulate the distribution of a seepage field in the power station region.

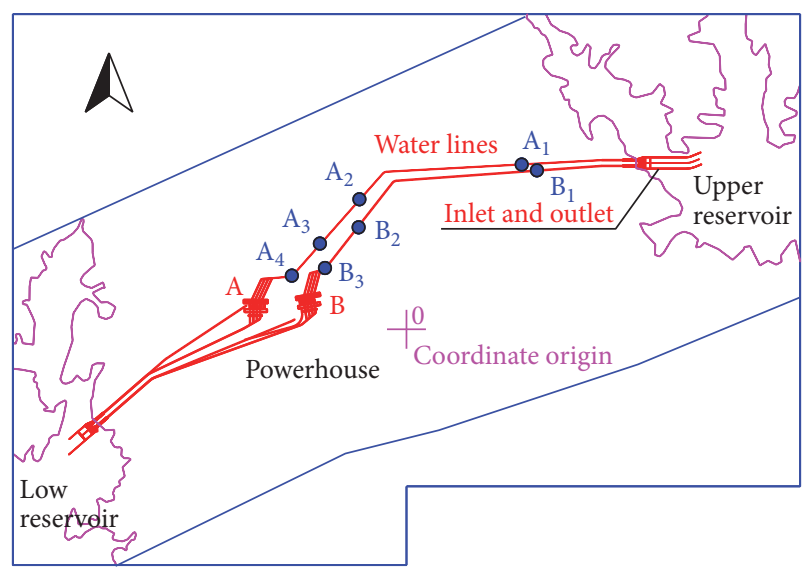

FIGURE 6: Layout of the Huizhou pumped storage power station.

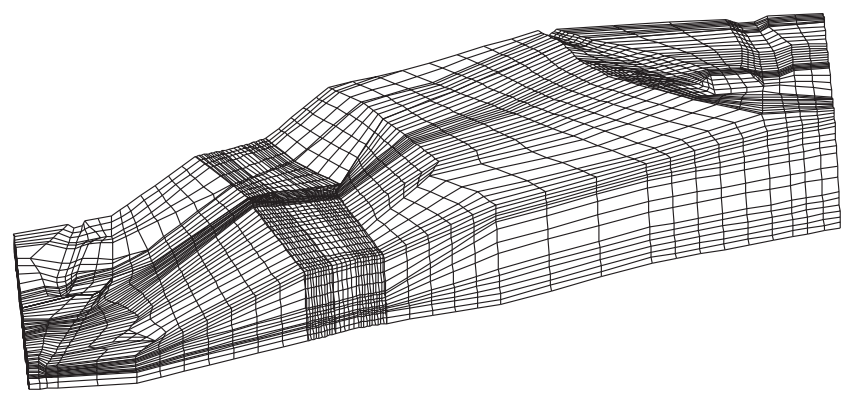

(a) Equivalent continuum media model

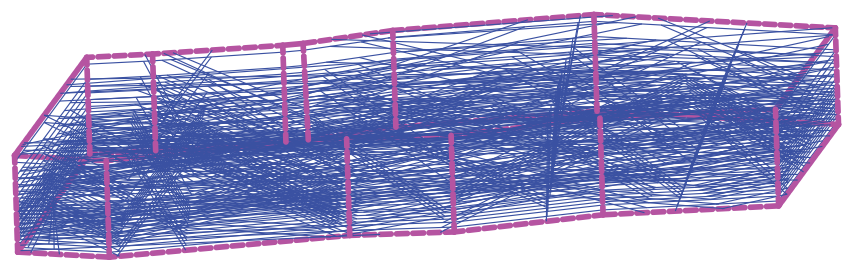

(b) Discrete network model

FIGURE 7: The discrete model of the study domain.

The study domain was meshed into 42,765 elements including 47,216 nodes when using the equivalent continuum media model, as shown in Figure 7(a). The study indicated that 40 fracture surfaces and 2362 fracture network intersections were formed using a coupled discrete media model, as shown in Figure 7(b).

\section{Data Analysis}

4.1. Determination of Hydrogeological Parameters. A series of water pressure tests could be conducted in the study area and the hydraulic conductivity was calculated through analyzing the outcomes of pump-in tests. This can be written as

$$
K=1.67 \times 10^{-3} \cdot \frac{\left(1+\ln \left(L / 2 r_{0}\right)\right)}{2 \pi} \cdot \omega,
$$

where $K$ is the hydraulic conductivity of a fractured rock mass $(\mathrm{cm} / \mathrm{s}), \omega$ is the water unit-absorption rate $(\mathrm{l} / \mathrm{min} \cdot \mathrm{m} \cdot \mathrm{m}), L$ is 
TABLE 1: Hydraulic conductivity in each plant zone.

\begin{tabular}{|c|c|c|c|c|}
\hline Division of water permeability & Strongly weathered zone & Weak weathered zone & Slightly weathered zone & Lining \\
\hline Permeability coefficient $(\mathrm{cm} / \mathrm{s})$ & 0.729 & 0.041 & 0.012 & 0.00864 \\
\hline
\end{tabular}

TABLE 2: Geometrical parameters of the fractures.

\begin{tabular}{|c|c|c|c|c|c|}
\hline \multirow{2}{*}{ Probability parameters } & \multicolumn{5}{|c|}{ Geometrical parameters } \\
\hline & Strike angle $\left({ }^{\circ}\right)$ & Dip direction angle $\left({ }^{\circ}\right)$ & Dip angle $\left(^{\circ}\right)$ & Distance $(\mathrm{m})$ & Broken zone $(\mathrm{m})$ \\
\hline \multicolumn{6}{|l|}{ Mean value } \\
\hline NE & 50.4 & 140.4 & 69.6 & 123.9 & 1.03 \\
\hline NW & 313.3 & 223.3 & 75.2 & 145.4 & 1.27 \\
\hline \multicolumn{6}{|l|}{ Standard deviation } \\
\hline $\mathrm{NE}$ & 11.92 & 11.92 & 7.45 & 67.83 & 0.9 \\
\hline NW & 9.76 & 9.76 & 8.63 & 84.12 & 1.07 \\
\hline \multicolumn{6}{|l|}{ Distribution form } \\
\hline $\mathrm{NE}$ & Normal distribution & Normal distribution & Normal distribution & Negative exponent & Negative exponent \\
\hline NW & Normal distribution & Normal distribution & Normal distribution & Negative exponent & Negative exponent \\
\hline
\end{tabular}

the length of a test segment $(\mathrm{m})$, and $r_{0}$ represents the radius of a borehole (m).

The rock mass can be classified into three zones which include a strongly weathered zone, a weak weathered zone, and a slightly weathered zone in a vertical direction based on the properties of the rock mass structure and various characteristics of the rock properties. Based on the unit water absorption rate and results from tests in each zone, the hydraulic conductivity in each calculating zone can be defined using (10), where the length of the test segment is $L=6 \mathrm{~m}$ and the radius of the borehole is $r_{0}=0.0375 \mathrm{~m}$. The hydraulic conductivity results in each zone are listed in Table 1 .

Two faults with NW and NE strikes were developed in the plant area. They are the main water control structures in the powerhouse domain. These two faults were considered when establishing the three-dimensional fracture network models. The geometric parameters, such as strike angle, dip direction angle, dip angle, space distance, and width of a broken area, were determined by statistical analysis. The probability distribution of these parameters was defined by analyzing the results of statistics from the foundation for a Monte-Carlo simulation. As listed in Table 2, fracture surfaces were randomly generated in the powerhouse domain using the mean value, variance, and distribution of fracture geometry parameters. These fracture surfaces developed a three-dimensional fractured network by crossing each other and reaching the boundary.

\subsection{Calculation and Prediction of External Water Pressure}

4.2.1. The Change of Internal Water Leakage Quantity after Water Filling in a Waterway System. During normal operation periods, water leakage occurs in the waterway through the steel concrete lining after water filling occurs in the waterway system where seepage goes from the inner to the outer waterway. The quantity of inner water leakage is related to the location of the waterway and time. Several key feature points along the waterway were selected to study the changing rule of inner water leakage (Figure 6). The water levels of the upper and lower reservoirs were $762 \mathrm{~m}$ and $205 \mathrm{~m}$, respectively, under normal conditions. The upper, middle, and lower stories of the galleries in powerhouses $\mathrm{A}$ and $\mathrm{B}$ discharge water. Waterproof curtains were set at both intersections and branches of high water pressure and water discharging galleries were built in a pilot tunnel at a height of $246 \mathrm{~m}$. Four feature points, A1, A2, A3, and A4, were selected from the water diversion tunnel to the high water pressure tunnel in the underground waterway system for powerhouse A. Points A1, A2, A3, and A4 were located at the upper tunnel, middle inclined shaft, lower inclined shaft, and lower tunnel with heights of $590 \mathrm{~m}, 458 \mathrm{~m}, 146 \mathrm{~m}$, and $135 \mathrm{~m}$, respectively. Points B1, B2, and B3 were selected as three feature points in the underground waterway system for powerhouse B from the water diversion tunnel to a high water pressure tunnel. They were located in the upper tunnel, middle inclined shaft, and lower tunnel with heights of $590 \mathrm{~m}, 458 \mathrm{~m}$, and $135 \mathrm{~m}$, respectively.

Figure 8 shows the changing relationship of internal water leakage over time in a waterway system. The flow quantity at time 0 represents the leakage at the beginning and was calculated at a water level of $762 \mathrm{~m}$ in the waterway and a natural water level near the waterway.

The water table is predicted to rise because of inner water leakage, but the leakage quantity will be reduced after water fills into the waterway system for an entire workday. The amount of leakage is higher in this situation than leakage in natural conditions due to water discharge in high water pressure branch pipes and powerhouses. This results in a rise of the water table below the natural water level, although inner water leakage exists in the waterway system. Thus, the water level along the waterway rises gradually, the hydraulic head pressure difference was reduced, and the amount of leakage decreased. At one point it even decreased to 0 over time in the waterway system.

Different amounts of inner water leakage exist at varying points in the waterway systems. The amount of water leakage 


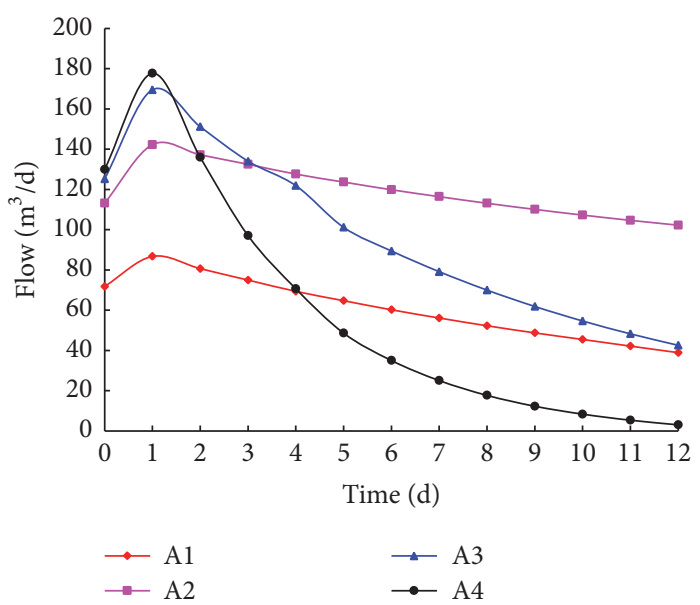

(a) Flow of the water diversion system in powerhouse $\mathrm{A}$

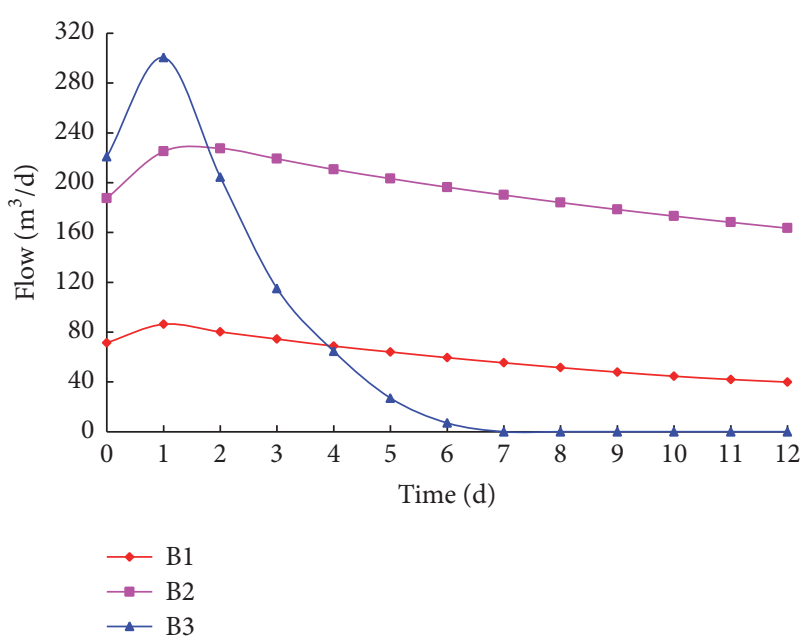

(b) Flow of the water diversion system in powerhouse B

FIGURE 8: Change of inner water leakage in the waterway system with time.

progressively increases as the groundwater table decreases from the water diversion tunnel to a high water pressure tunnel in natural conditions. As the groundwater level remained high in the upper tunnel and the middle inclined shaft, the hydraulic head differences became smaller and the groundwater level remained low in the lower tunnel and lower inclined shaft. The hydraulic head difference became larger after water filled the waterway system, at which point the inner water leakage amplitude of variation decreased in the upper tunnel and the middle inclined shaft, while it increased in the lower tunnel and lower inclined shaft.

\subsubsection{Influence of Internal Water Leakage on External Water} Pressure of the Steel Branch Pipes. Inner water leakage not only increased the amount of water discharge in the powerhouse and high pressure branch pipes, but also raised the external water pressure of the steel branch pipes. The inner water pressure decreased to 0 when the waterway was vented in a short time because of external water pressure. The hydraulic head in the waterway system acted on the surface of the steel branch pipes directly. This may lead to the damage of the steel branch pipes if the pressure at the hydraulic head exceeded the tolerable pressure of the steel branch pipes, and the routine water drainage system is used to reduce external water pressure on the steel branch pipes. A cross-section taken approximately vertical to the steel branch pipes before the drainage hole and after the high water pressure was used to calculate external water pressure (Figure 9), with the unit of contour value as MPa.

The water pressure was calculated after cracking of the reinforced concrete lining. The external water pressure on the steel branch pipes decreased to almost 0 owing to the anti-seepage and drainage in the high pressure branch pipes. The maximum external water pressure is $1.2 \mathrm{MPa}$, which satisfies the design value (i.e., it was below 1.8 MPa). Ensuring the normal operation of reinforced concrete is important as the external water pressure can reach $1.6 \mathrm{MPa}$ when the reinforced concrete is destroyed and this amount exceeds the

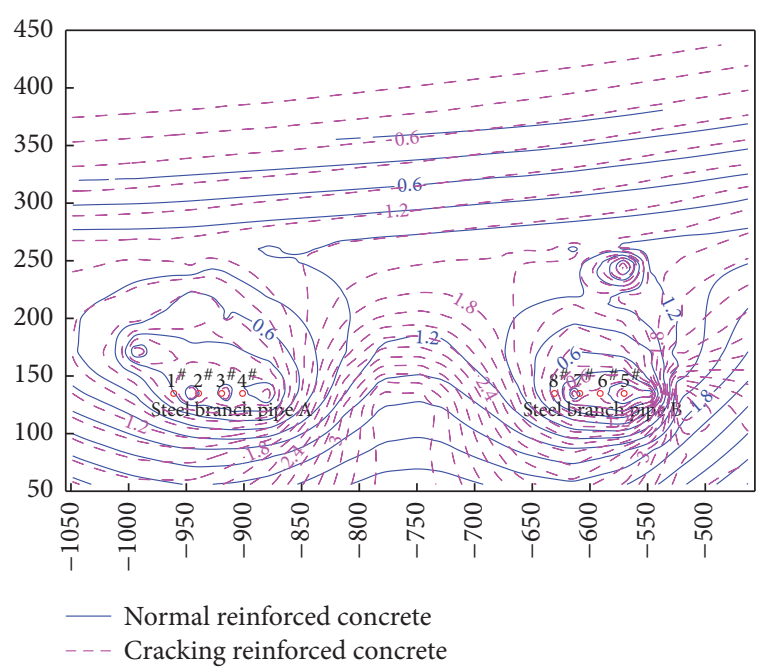

FIGURE 9: Contour map of external water pressures.

designed value. In addition, external water pressures in these parts are almost 0 because the water discharge in the $246 \mathrm{~m}$ high gallery and external water pressure were also reduced above the height of $246 \mathrm{~m}$.

\subsubsection{Change in the External Water Pressure of the Waterway} System on Venting Conditions. The water level inside the waterway decreased at a rate of $20 \mathrm{~m}$ per hour when the waterway system was venting, while the water level outside the waterway decreased at a very low speed because of the antiseepage effect of the concrete lining. The difference between the inner and outer water pressure resulted in an external water pressure. Water in the waterway system was vented over 38 hours, as shown in Figures 10 and 11, to reveal the external water pressure changes over time in powerhouses $A$ and $B$ during waterway system venting. Figure 10 shows the change in external water pressure when cracking occurred in 


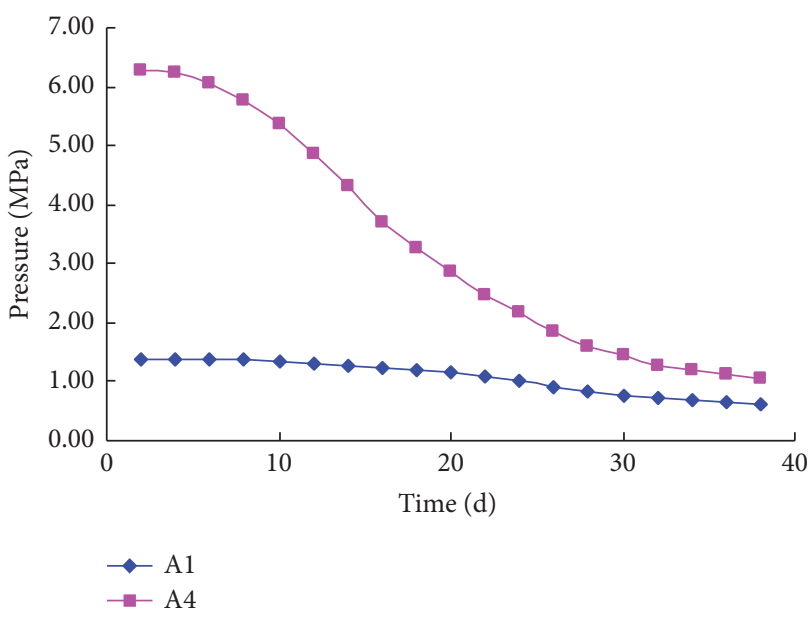

(a) Pressure of water diversion system in powerhouse $\mathrm{A}$

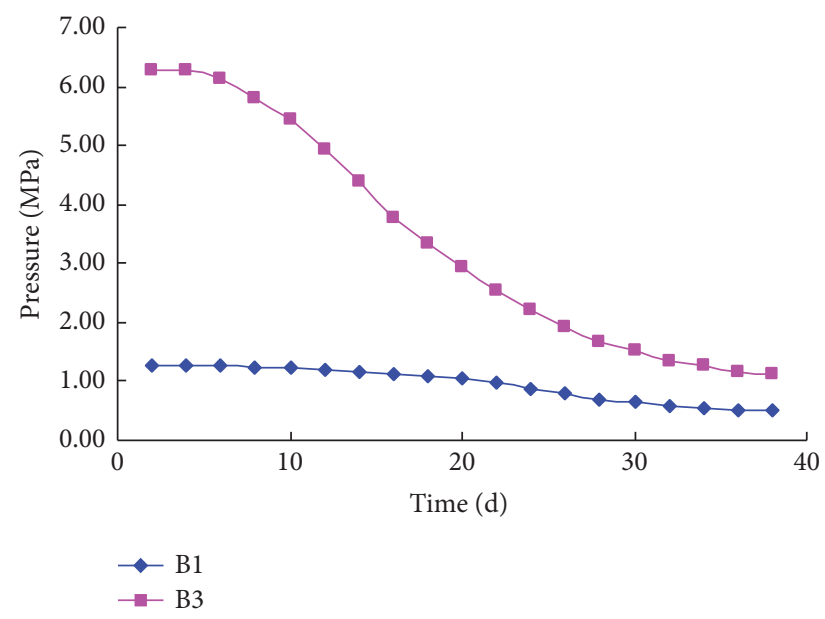

(b) Pressure of the water diversion system in powerhouse B

FIGURE 10: External water pressure changes with time when the waterway system was vented after the cracking of reinforced concrete.

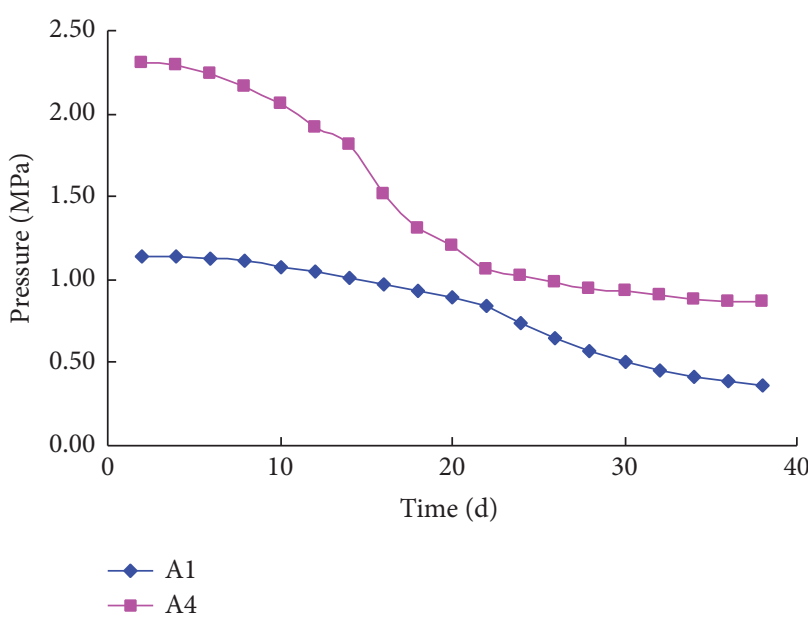

(a) Pressure of water diversion system in powerhouse A

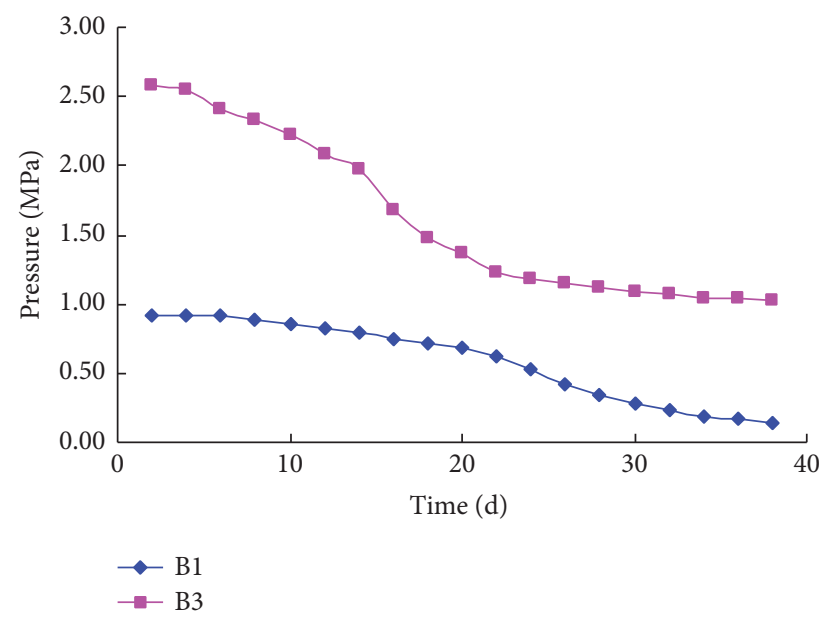

(b) Pressure of water diversion system in powerhouse B

FIGURE 11: External water pressure changes with time when the waterway system was vented with normal reinforced concrete.

the concrete lining. Figure 11 shows the outcome when the concrete lining remained effective. As illustrated in Figure 10, external water pressures in $\mathrm{A} 1$ and $\mathrm{B} 1$ were $0.63 \sim 1.40 \mathrm{MPa}$ and $0.51 \sim 1.28 \mathrm{MPa}$, respectively. The maximum value and amplitude of variation were both small and external water pressure was insufficient to damage the waterway system because the elevation in these places was $590 \mathrm{~m}$. For A4 and B3, the elevation was $135 \mathrm{~m}$ and the external water pressure was large near the steel branch pipes. However, with the venting of the waterway system, external water pressure gradually decreased. The tensile and compressive strengths of the surrounding rock in the waterway system were high, especially for complete granite. Therefore, since the minimum value of the tensile and compressive strengths of the surrounding rock was greater than $7 \mathrm{MPa}$, external water pressure caused by waterway system venting will not damage the waterway system.

External water pressure in Figure 11 was smaller when compared with Figure 10. It increased slightly due to the antiseepage effect of the concrete lining when the waterway system was filling with water, and a small increase in external water pressure occurred when the waterway system was vented. The maximum external water pressure was below 2.7 $\mathrm{MPa}$, as shown in Figure 11.

\subsubsection{Change in External Water Pressure When Only One} Powerhouse Was Operating. Powerhouse A was operated while the waterway system was filling with water and the waterway system in powerhouse B was venting. Water in the waterway system of powerhouse A seeped from the inner to an outer tunnel. Under these conditions, the external water pressure caused by venting water in the waterway system of powerhouse B was calculated. The results showed that the external water pressure on the water diversion tunnel in powerhouse $\mathrm{B}$ was $0.3 \sim 1.34 \mathrm{MPa}$, and the external water pressure on the high pressure tunnel in powerhouse $B$ was $0.8 \sim 1.63 \mathrm{MPa}$. Through the rock material of the tunnel and the powerhouse, the rock mass along the two sides of the 
waterway system in powerhouse B was relatively intact, even in the absence of any concrete lining. The surrounding rock was stable, and the main formation lithology was granite with high compressive and tensile strength. Therefore, the external water pressure would not destroy the waterway system when water is vented from the waterway in powerhouse B. For water venting in the waterway system of powerhouse $B$, the waterway will be subject to external water pressure and water will seep from the outer to the inner tunnel opposite to powerhouse A.

When the waterway system in powerhouse B was operated and the waterway system in powerhouse A was vented, the external water pressure and quantity of external water infiltration were analyzed. The external water pressure in the water diversion tunnel of powerhouse A was $0.31 \sim 1.34 \mathrm{MPa}$, and the external water pressure in the high pressure tunnel of powerhouse A was 0.91 2.17 MPa. Although external water pressure in the high pressure tunnel of powerhouse A was relatively greater than those of other cases, it was below the compressive strength of the surrounding rocks in the waterway system. Most importantly, external water pressure caused by water venting around the waterway system of powerhouse A will not destroy the waterway system.

\section{Conclusions}

Groundwater movement in fractured rocks was simulated and calculated using a coupled model to determine the external water pressure in the powerhouse and high pressure branch pipes under normal conditions. The results show that the external water pressure of the waterline ranged from 0.2 to $2.12 \mathrm{MPa}$ during normal operation of the reservoir. The values were lower than the compressive strength of the surrounding rock and reinforced concrete at $2.3 \mathrm{MPa}$. In addition, the external water pressure of the powerhouse and steel branch pipes ranged from 1.4 to $1.72 \mathrm{MPa}$, which was also smaller than the designed external water pressure of 1.80 MPa. Therefore, the external water pressure will not destroy the waterline, powerhouse, and steel branch pipes and seepage failure will not occur in these parts. However, if the concrete lining was cracking, the increased amplitude of the external water pressure will be increased from 18.4 to $121.2 \%$. This pressure on the steel branch pipes was over 2.0 $\mathrm{MPa}$ which is higher than the designed value and may damage the steel branch pipes. External water pressure was higher when operating two powerhouses than the case that only one powerhouse was operated; therefore, the external water pressure while emptying the waterway was lower than the strength of the waterway system itself and the vented waterway will not be destroyed by external water pressure.

\section{Competing Interests}

The authors declare that they have no competing interests.

\section{Acknowledgments}

This study was financially supported by a senior visiting scholar training project in domestic universities in Jiangsu
Province (2014-2015), a producing, learning, and researching project from the Science and Technology Department in Jiangsu Province (2015-2016), the Department of Housing Construction (2014-2015), and the Ministry of Housing Construction (2015-2016) and sponsored by Qing Lan Project of Jiangsu Province.

\section{References}

[1] J. Y. Wang, "Problems of external water pressure on tunnel lining," Railway Construction Technology, vol. 2, pp. 1-6, 2008.

[2] X. Y. Wang, Z. S. Tan, M. S. Wang, M. Zhang, and H. F. Ming, "Theoretical and experimental study of external water pressure on tunnel lining in controlled drainage under high water level," Tunnelling and Underground Space Technology, vol. 23, no. 5, pp. 552-560, 2008.

[3] X. M. Zhang, Z. M. Jiang, S. R. Feng, and S. H. Chen, "Study on the determination of permeability coefficient of fractured rock mass under high pressure test condition," Journal of Hydroelectric Engineering, vol. 30, no. 1, pp. 155-159, 2011.

[4] B. Huang, P. Li, J. Ma, and S. Chen, "Experimental investigation on the basic law of hydraulic fracturing after water pressure control blasting," Rock Mechanics and Rock Engineering, vol. 47, no. 4, pp. 1321-1334, 2014.

[5] H. S. Lee, Y. J. Lee, S. W. Seo, and Y. C. Hwang, "A study on the treatment of external water pressure for the water pressure tunnel at the structural analysis of concrete lining," Journal of Korean Tunnelling and Underground Space Association, vol. 17, no. 6, pp. 653-664, 2015.

[6] Y. T. Zhang, "The correction factor of external water pressure in the design of tunnel and penstock," Water Power, vol. 12, pp. 30-34, 1996.

[7] Y. T. Zhang, "Discussion on external hydraulic pressure upon rock tunnel lining," Modern Tunnelling Technology, vol. 03, pp. $1-4,2003$.

[8] B. S. Guan, "Study on soil pressure of the Qinghan TunnelChapter 8 pressure on tunnel lining," Tunnel, vol. 10, pp. 38-50, 1980.

[9] J. H. Shin, Y. S. Shin, S. H. Kim, and H. S. Shin, "Evaluation of residual pore water pressures on linings for undersea tunnels," Chinese Journal of Rock Mechanics and Engineering, vol. 26, no. 2, pp. 3682-3688, 2007.

[10] C. Xin, B. Gao, C. Sui, and Y. Zhou, "Analysis of external water pressure on the support and lining of deep mountain tunnels below high water tables," Journal of Highway and Transportation Research and Development (English Edition), vol. 8, no. 1, pp. 6166, 2014.

[11] R. Guo and J. X. Zhou, "Analysis on the Factors affecting Water Pressure upon Composite Lining of Underwater Tunnel," Railway Standard Design, vol. 4, article 019, 2014.

[12] Y. W. Xiu and T. Zhongsheng, "Study on the characteristics of water pressure on the composite lining in underwater tunnels," Modern Tunnelling Technology, vol. 1, 014, 2015.

[13] Q. Pan and D. Dias, “The effect of pore water pressure on tunnel face stability," International Journal for Numerical and Analytical Methods in Geomechanics, vol. 40, no. 15, pp. 2123-2136, 2016.

[14] M. Huangfu, M.-S. Wang, Z.-S. Tan, and X.-Y. Wang, "Analytical solutions for steady seepage into an underwater circular tunnel," Tunnelling and Underground Space Technology, vol. 25, no. 4, pp. 391-396, 2010. 
[15] P. K. Shrestha and K. K. Panthi, "Groundwater effect on faulted rock mass: an evaluation of Modi Khola pressure tunnel in the Nepal Himalaya," Rock Mechanics and Rock Engineering, vol. 47, no. 3, pp. 1021-1035, 2014.

[16] F. Rueda, J. P. Torres, M. Machado, P. M. Frontini, and J. L. Otegui, "External pressure induced buckling collapse of high density polyethylene (HDPE) liners: FEM modeling and predictions," Thin-Walled Structures, vol. 96, pp. 56-63, 2015.

[17] Y. Q. Wu, "The coupled stress-groundwater flow model for jointed rock mass," Journal of Geological Hazards and Environmental Preservation, vol. 1, pp. 31-34, 1996.

[18] B. Zheng, J. Wang, and J. Wu, "A study of the applicability of an axisymmetric solution for calculating the water pressure on a tunnel lining," Modern Tunnelling Technology, vol. 49, pp. 1-6, 2012 (Chinese).

[19] W. Cui, X. Zhu, Y. Zhu, X. Cao, and M. Li, "Analysis on tunnel lining cracking caused by external water pressure in water-rich area," Water Resources and Hydropower Engineering, vol. 43, pp. 57-61, 2012 (Chinese).

[20] L. N. Lamas, N. S. Leitão, C. Esteves, and N. Plasencia, "First infilling of the Venda Nova ii unlined high-pressure tunnel: observed behaviour and numerical modelling," Rock Mechanics and Rock Engineering, vol. 47, no. 3, pp. 885-904, 2014.

[21] C. Qin, S. C. Chian, X. Yang, and D. Du, "2D and 3D limit analysis of progressive collapse mechanism for deepburied tunnels under the condition of varying water table," International Journal of Rock Mechanics and Mining Sciences, vol. 80, pp. 255-264, 2015.

[22] J. Noorishad, M. S. Ayatollahi, and P. A. Witherspoon, "A finiteelement method for coupled stress and fluid flow analysis in fractured rock masses," International Journal of Rock Mechanics and Mining Sciences and, vol. 19, no. 4, pp. 185-193, 1982.

[23] J. Noorishad, C. F. Tsang, and P. A. Witherspoon, "Coupled thermal-hydraulic-mechanical phenomena in saturated fractured porous rocks: numerical approach," Journal of Geophysical Research, vol. 89, no. 12, pp. 10365-10373, 1984.

[24] M. Oda, "Permeability tensor for discontinuous rock masses," Geotechnique, vol. 35, no. 4, pp. 483-495, 1985.

[25] U. Ohnishi and H. Ohtsu, "Coupled stress flow analysis of discontinuous media by finite elements," Proceedings of the Japan Society of Civil Engineers, vol. 322, pp. 111-120, 1982 (Japanese).

[26] Y. Q. Wu and C. Y. Zhang, An Introduction to Rock Mass Hydraulics, Science Press, Beijing, China, 1995.

[27] C. X. She and X. Cui, "Influence of high pore water pressure on creep properties of rock," Chinese Journal of Rock Mechanics and Engineering, vol. 29, no. 8, pp. 1603-1609, 2010.

[28] J.-H. Yoo, H.-S. Lee, and M. A. Ismail, "An analytical study on the water penetration and diffusion into concrete under water pressure," Construction and Building Materials, vol. 25, no. 1, pp. 99-108, 2011.

[29] D. Ma, X. X. Miao, Z. Q. Chen, and X. B. Mao, "Experimental investigation of seepage properties of fractured rocks under different confining pressures," Rock Mechanics and Rock Engineering, vol. 46, no. 5, pp. 1135-1144, 2013.

[30] C. X. Chen, W. B. Liu, and T. Peng, "A groundwater flow model for determining the external water pressure of tunnels," Hydrogeology and Engineering Geology, vol. 5, pp. 62-64, 2002.

[31] S. H. Wu, "Study of defining external water pressure with a hydro-geochemical method," Jiangsu Construction, vol. 3, pp. 32-35, 2005.
[32] Y. Huang, Z. Yu, and Z. Zhou, "Simulating groundwater inflow in the underground tunnel with a coupled fracture-matrix model," Journal of Hydrologic Engineering, vol. 18, no. 11, pp. 1557-1561, 2013. 

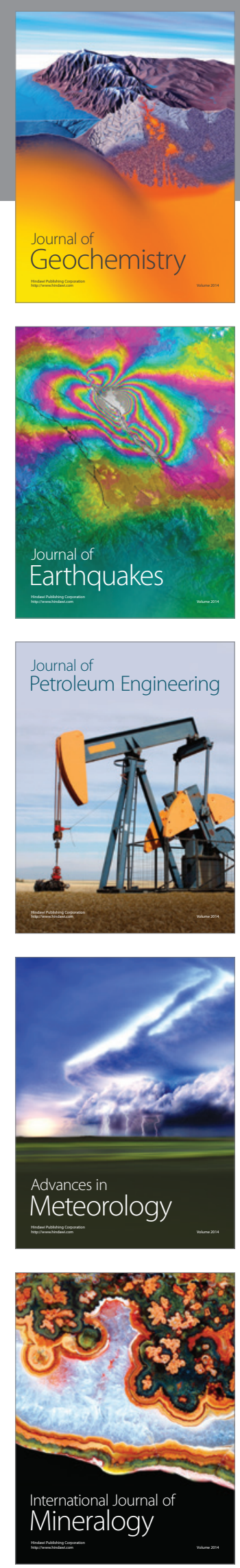
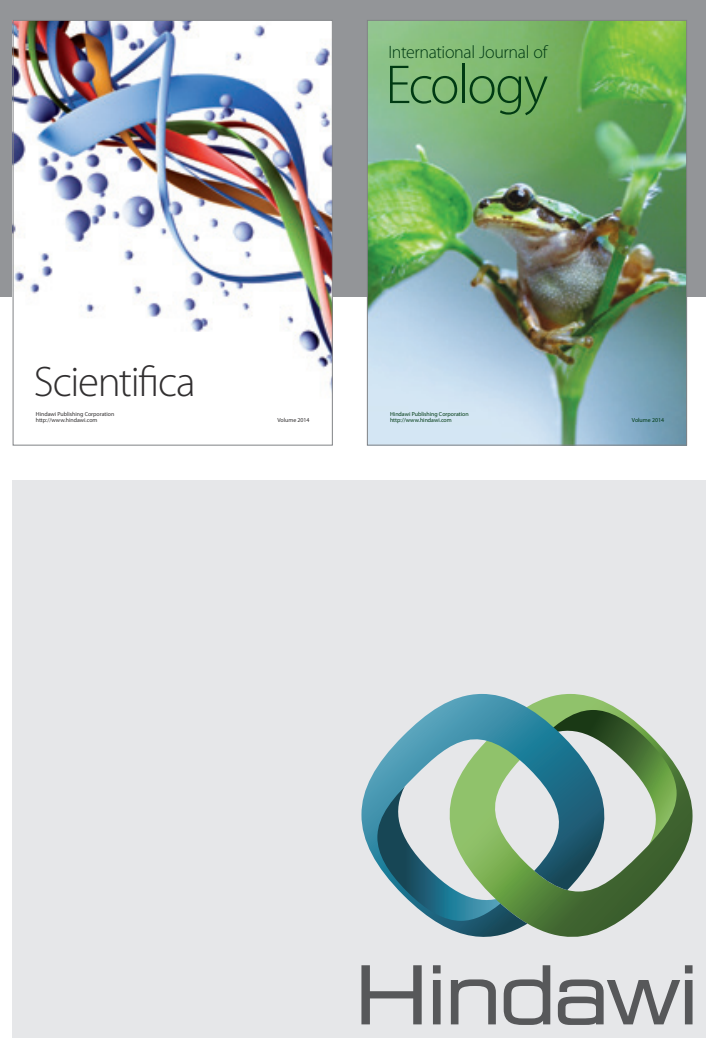

Submit your manuscripts at

https://www.hindawi.com
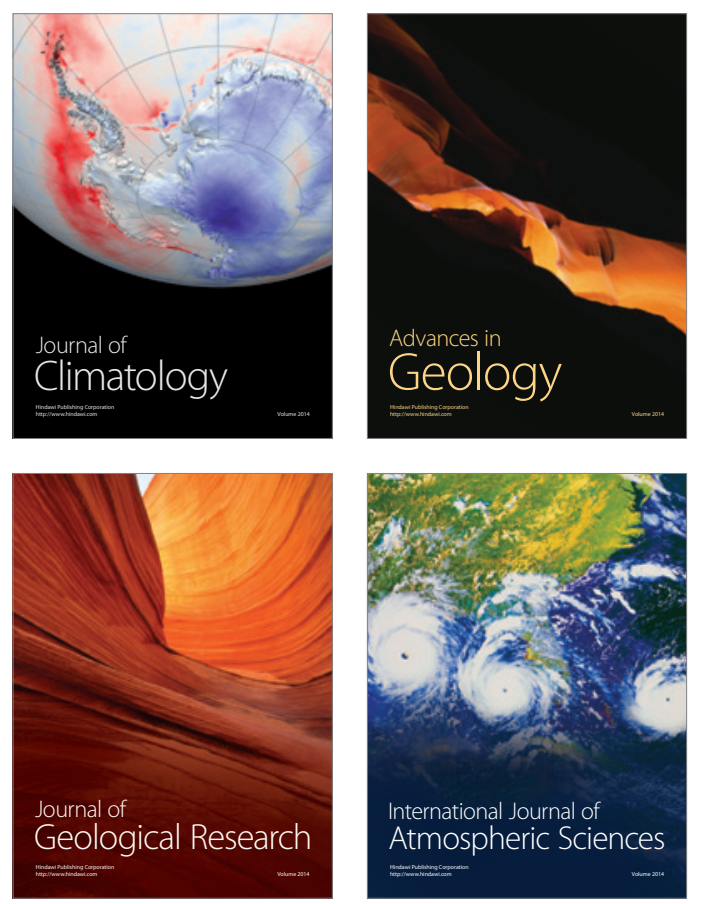

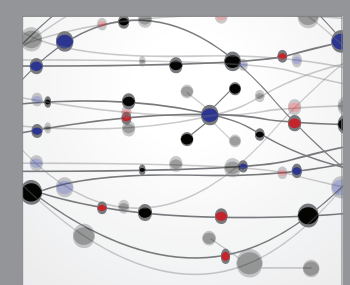

The Scientific

\section{World Journal}
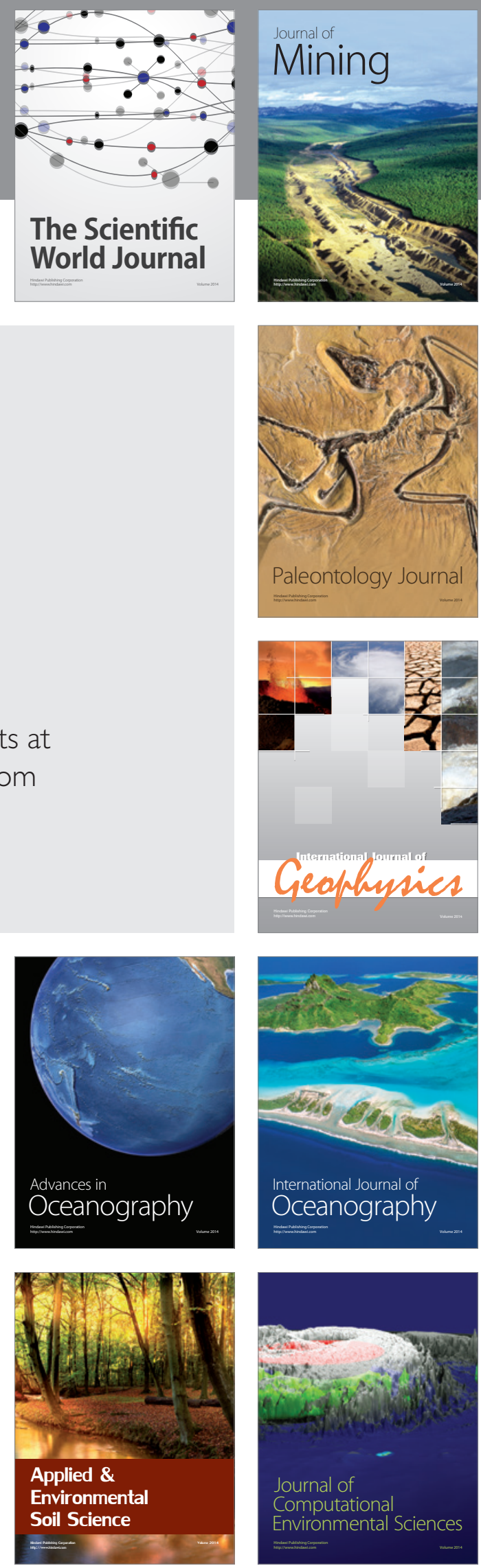